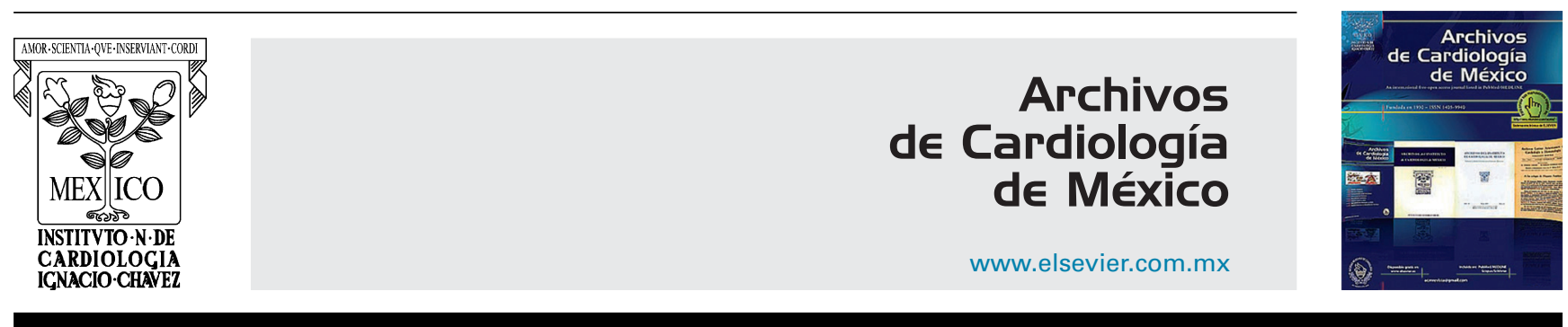

IMAGE IN CARDIOLOGY

\title{
The use of cardiac CT as a roadmap for resolving coronary stent dislodgement
}

\section{El Uso de TC Cardiaca como Guía para Resolución de un Stent Coronario Dislocado}

\author{
Guillermo Torre-Amione ${ }^{\mathrm{a}, \mathrm{b}, \mathrm{c}}$, Erasmo de la Pena-Almaguer ${ }^{\mathrm{a}}$, Juan Quintanilla ${ }^{\mathrm{a}}$, \\ Felipe Valdes $^{\mathrm{a}}$, Vicente Jimenez ${ }^{\mathrm{a}}$, David Rodriguez ${ }^{\mathrm{a}, \mathrm{b}}$, Alejandro Trevino ${ }^{\mathrm{a}}$, \\ Luis Perez $^{\mathrm{a}}$, Carlos Jerjes-Sanchez ${ }^{\mathrm{a}, \mathrm{b}, *}$
}

\author{
a Instituto de Cardiología y Medicina Vascular, TEC Salud, San Pedro Garza García, Nuevo León, Mexico \\ b Centro de Investigación Biomédica, Hospital Zambrano Hellion, TEC Salud, Escuela de Medicina, Tecnológico de Monterrey, San \\ Pedro Garza García, Nuevo León, Mexico \\ ' Methodist DeBakey Heart and Vascular Center, The Methodist Hospital, Houston, TX, United States
}

Received 12 February 2018; accepted 25 March 2018

Stent dislodgement of an unexpanded stent is a rare and potentially severe complication of percutaneous coronary interventions that can result in emergent coronary artery bypass graft surgery, embolization, or death. ${ }^{1}$ Several approaches have been used to identify and resolve this unusual complication; however, the best strategy, as well as the role of cardiac computed tomography (CT) in this clinical scenario, remains unknown. We report the case of an 83-year-old male with the previous history of ischemic heart disease, paroxysmal atrial fibrillation, and stroke. The patient underwent failed percutaneous coronary intervention of a proximal heavily calcified lesion in the left anterior descending coronary artery, which resulted in the dislodgment of a $2.5 \mathrm{~mm} \times 2.5 \mathrm{~mm}$ unexpanded stent. The initial coronary angiography was not able to determine whether the stent was in the left main or ostial left anterior descending (Fig. 1A). A coronary CT angiography was used to help determine the exact location and drive approach, which in this case was the ostial left anterior descending (Fig. 1B-E). The patient underwent successful coronary stent deployment to crush the unexpanded stent against the vessel wall by deploying a second stent and was discharged home after a 24-h stay. Coronary CT angiography is a suitable strategy to this unusual stenting complication. A thorough search of the literature was not able to identify previously published reports describing the use of cardiac coronary CT angiography to identify a dislodged coronary stent and help drive treatment.

\footnotetext{
* Corresponding author at: Batallón de San Patricio 112, Real San Agustin, CP 66278 San Pedro Garza García, Nuevo León, Mexico.

E-mail addresses: jerjes@prodigy.net.mx, carlos.jerjes@udicem.org.mx (C. Jerjes-Sanchez).
} 

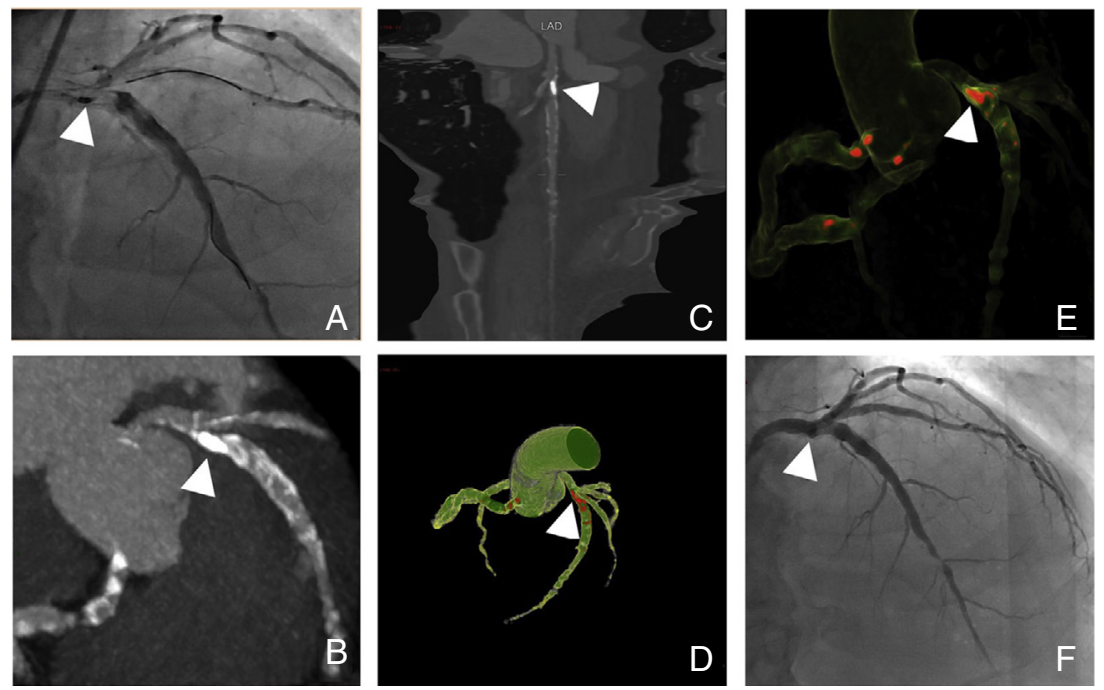

Figure 1 Coronary and cardiac CT angiography showing stent dislodgement location and resolution. (A) Conventional coronary angiography showing the dislodged stent in the ostial left anterior descending (arrow) as well as a heavily calcified lesion on its proximal portion and guide-wires protecting left anterior descending and circumflex arteries. A heterogeneous contrast filling is noted on the left anterior descending. Overlapping of coronary arteries does not allow to determine exact location of the stent. (B-E) Show curved planar, volume rendering and maximum intensity coronary CT angiography reconstructions, portraying the unexpanded stent in the ostial left anterior descending artery. (F) Conventional coronary angiography is showing the result after stent deployment with the unexpanded stent.

\section{Reference}

1. Burak A, Ertuğgrul 0 , İran Ş, et al. Dislodgement of coronary stent due to rupture of stent ballon. Arch Turk Soc Cardiol. 2015;43:93-4. http://www. journalagent.com/tkd/ pdfs/TKDA_43_1_93_94.pdf 